\title{
Redox Coupled Ion Exchange in Copolymers of Aniline with Aminobenzoic Acids
}

\author{
H.J. Salavagione, D.F. Acevedo, M.C. Miras, C. Barbero * \\ Departamento de Química, Universidad Nacional de Río Cuarto, \\ Agencia postal No 3, 5800 - Rio Cuarto, Argentina
}

Received 30 December 2002; accepted in revised form 5 May 2003

\begin{abstract}
Copolymers of aniline and 2-aminobenzoic acid are prepared by chemical copolymerization. The copolymers are soluble in basic media and thin films are prepared, onto glassy carbon electrodes, by evaporation of the solutions. The modified electrodes show a voltammetric response, with two peaks, similar to polyaniline with two peaks. The dependence of both peak potentials on $\mathrm{pH}$ is similar to that of PANI, suggesting that proton expulsion is the mechanism of charge compensation on oxidation. The mechanism is confirmed by Probe Beam Deflection, which shows proton expulsion on oxidation. However, while polyaniline films exchange mainly anions at $\mathrm{pH}>0$, poly(aniline-co-(2-aminobenzoic acid)) ( $2 \mathrm{ABA})$ film exchange protons up to $\mathrm{pH} 4$.
\end{abstract}

Keywords: polyaniline, $\mathrm{pH}$, ion exchange, aminobenzoic, probe beam deflection.

\section{Introduction}

The copolimerization of substituted anilines with aniline allows to change the properties of the homopolymer (polyaniline, PANI) by incorporation of functional groups in the polymer backbone. By incorporation of anionic groups (eg. $-\mathrm{SO}_{3}^{-}$) [1] it has been possible to improve the solubility of the polymer in aqueous solution [2], to increase the specific charge for battery applications [3] and to alter the redox coupled ion exchange [4]. Copolymerization allows to produce polymer from monomers unable to homopolymerize. Using that synthetic method, aminobenzoic acids have been copolymerized chemically [5]

\footnotetext{
* Corresponding author. E-mail address: cbarbero@exa.unrc.edu.ar
} 
and electrochemically [6] with aniline. Recently the electrochemical polymerization of $\mathrm{o}, \mathrm{m}$ and $\mathrm{p}$-aminobenzoic acids was studied [7]. In the present communication, the redox coupled ion exchange in copolymers of 2aminobenzoic acid and aniline is described. The copolymers are produced chemically, to control the amount of aminobenzoic acid incorporated into the polymer. The redox coupled ion exchange in aqueous media was studied by cyclic voltammetry and Probe Beam Deflection. The latter is an optical technique that has been extensively used to study redox coupled ion exchange in electroactive polymers [8].

\section{Experimental}

All solutions were produced using ultrapure (Millipore) water and analytical quality reagents. All potentials are reported against saturated calomel electrode (SCE) as reference.

\section{Copolymerization}

Chemical copolymerization of aniline and aminobenzoic acids were carried out in a stirred $1 \mathrm{~L}$ reactor at $0{ }^{\circ} \mathrm{C}$ (ice/water bath). The monomer mixture $(0.1 \mathrm{M}$ total concentration) was dissolved in $1 \mathrm{M} \mathrm{HCl}$ and an equimolar amount of ammonium persulfate is added. When the reaction finished, the suspended solid is filtered off and washed with $1 \mathrm{M} \mathrm{HCl}$ and water. The copolymer is then dried under dynamic vacuum.

In all the experiments described in this communication, the copolymer was prepared with a ratio aniline/aminobenzoic acid of 1:1.

\section{Film Formation}

The copolymer powder was dissolved in $0.1 \mathrm{M} \mathrm{NH} 3$ water solution. A measured amount of solution was deposited onto a glassy carbon electrode and the solvent evaporated with the aid of an infrared lamp. The ammonium salt of the copolymer decomposes and the acid form (insoluble in acid media) remains on the electrode. 


\section{Cyclic voltammetry}

The electrochemical experiments were performed using a GAMRY PC4/750 potentiostat controlled by a personal computer. A conventional three electrode cell was used with a Pt wire as counter electrode and a saturated calomel electrode as reference. The working electrode materials were either GC or Pt. The GC electrodes were GC disks made by pressing a $3 \mathrm{~mm}$ diameter glassy carbon rod inside a Teflon tube $(2.95 \mathrm{~mm}$ internal diameter). The electrode surface was polished with alumina powder (down to $1 \mu \mathrm{m}$ ). The $\mathrm{pH}$ was maintained using universal buffers. A $2 \mathrm{M} \mathrm{NaCl}$ concentration of added salt was used to maintain constant ion strength. The $\mathrm{pH}$ was measured using a glass electrode and $\mathrm{pH}$ meter (Metrohm).

\section{Probe Beam Deflection}

Probe Beam Deflection experiments were carried out in an experimental set-up similar to the one described previously [9]. The PBD signals were recorded with an $\mathrm{X}-\mathrm{Y}-\mathrm{Y}^{\prime}$ recorder (Yokogawa 3023) along with the voltammograms. The electrochemical cell was a conventional optical glass cuvette $(2 \times 2 \times 4 \mathrm{~cm})$. A glassy carbon plate ( $1 \mathrm{~cm}$ wide) was used as the working electrode. The back side and edges were covered with an insulating lacquer (Lacomit). The plate was polished with diamond pastes with particle sizes decreasing down to $1 \mathrm{~mm}$. The counter-electrode was a $\mathrm{Pt}$ wire. In aqueous solutions $\beta \mathrm{Pd}-\mathrm{H}_{2}$ was used as the reference electrode. The distance between counter and working electrode was large enough to exclude any interference with the laser beam of the reactions occurring at the counter electrode. The PBD experiments were controlled by an AMEL 2049 potentiostat connected to a PAR 175 programmer.

Probe Beam Deflection is a technique that measures the concentration gradient in front of the electrode by monitoring the refractive index gradient with a light beam [10]. The electrochemical oxidation-reduction process in an electroactive

film is accompanied by a counterion exchange with the bathing solution to maintain film electroneutrality. The ion concentration in the solution changes, 
creating a gradient of refractive index normal to the electrode surface. A beam travelling parallel to the surface suffers a deviation proportional to the concentration gradient, therefore proportional to the extent and direction of ion flux. Positive beam deflection (away from the electrode) corresponds to the insertion of ions in the film while negative deflection (towards the electrode) implies release of ions to the solution.

\section{Results and Discussion}

A typical cyclic voltammogram of a poly(aniline-co-(2-aminobenzoic acid)) (p2ABA) modified electrode can be seen in Fig. 1 (full black line).

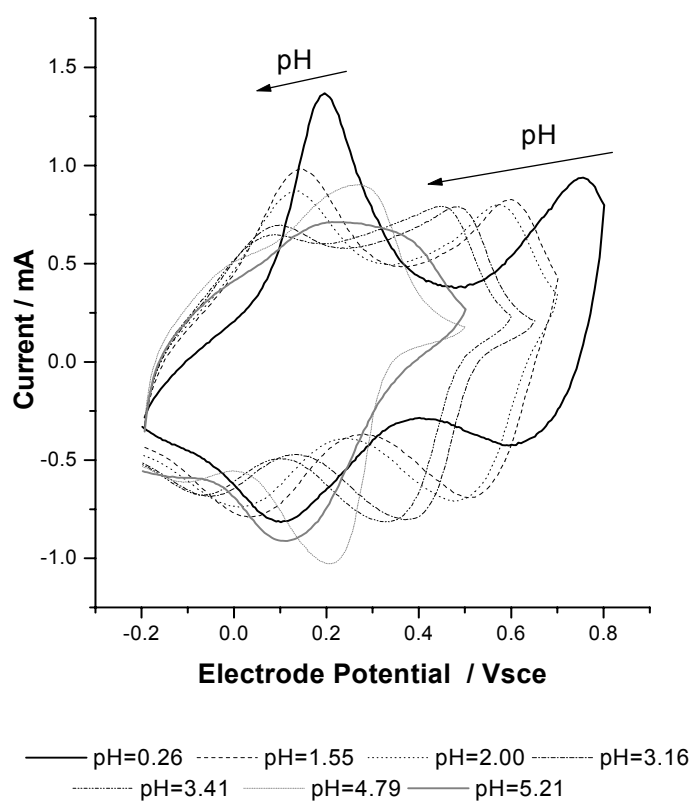

Figure 1. Cyclic voltammograms of GC electrodes modified with poly(aniline-co-(2aminobenzoic)) (1:1) (p2ABA11) thin films in buffered solution of different $\mathrm{pH}$ with 2 $\mathrm{M} \mathrm{NaCl}$ of added salt. Scan rate $=50 \mathrm{mV} / \mathrm{s}, \mathrm{T}=25^{\circ} \mathrm{C}$.

Two voltammetric peaks are observed corresponding to the oxidation transition from leucomeraldine to emeraldine and emeraldine to pernigraniline, respectively.

The cyclic voltammograms are strongly affected by the $\mathrm{pH}$ of the solution (Fig. 1). Both the potentials for the first and second redox peaks became more positive when the $\mathrm{pH}$ is increased. It is possible to write the Nernst equation for the system as (1): 


$$
E_{p}=E^{o}+\frac{0.059}{n_{e}} \log \left(\frac{\left[P_{O x}\right]}{\left[P_{\mathrm{Re} d}\right]}\right)+\frac{0.059}{n_{e}} \log \left(\left[\mathrm{A}^{-}\right]^{n_{A}}\left[\mathrm{C}^{+}\right]^{n_{C}}\right)-0.059 \frac{n_{H}}{n_{e}} \log \left(\mathrm{H}^{+}\right)
$$

If the concentration of ions: $\mathrm{A}^{-}, \mathrm{C}^{+}$(other than $\mathrm{H}^{+}$) is high and constant, and assuming that, in the peak potential, the surface concentration of oxidized polymer $\left(\mathrm{P}_{\mathrm{Ox}}\right)$ is equal to that of the reduced polymer (Pred), equation (1) reduces to:

$$
E_{p}=E_{f}-0.059 \frac{n_{H}}{n_{e}} \mathbf{p H}
$$

where $\mathrm{E}_{f}$ contains all terms not affected by the $\mathrm{pH}$. From the slope of $\mathrm{E}_{p} \mathrm{vs} . \mathrm{pH}$ lines, it is possible to calculate the ratio: $\mathrm{n}_{\mathrm{H}} / \mathrm{n}_{\mathrm{e}}$.

The experimental points for p2ABA, obtained from Fig. 1, are shown in Fig. 2. The data for PANI, from literature [11], are shown for comparison. As it can be seen, both the first and second redox processes show similar behaviour in p2ABA and PANI. However, the peak potential of p2ABA shifts with a slope of $0.037 \mathrm{~V} / \mathrm{pH}$ up to $\mathrm{pH} 3.5$ while in PANI the peak potential remains almost constant while the $\mathrm{pH}$ is increased from 0 to 4 .

In Table 1 are shown the slopes and ion exchange assignment, in each case.

The redox coupled ion exchange during the first redox peak is also tested using PBD (Fig. 3). To the voltammetric oxidation peak corresponds a negative deflection peak. Therefore, protons are expelled on oxidation during the first redox process. The opposite behaviour was observed in the same solution $(\mathrm{pH}=$ 1), the PBD response of PANI only shows positive deflection, indicative of dominant anion insertion [12]. 
Table 1. Dependence of the peak potential on $\mathrm{pH}$ for both redox processes in $\mathrm{p} 2 \mathrm{ABA}$ and PANI.

\begin{tabular}{ccccc}
\hline Polymer & Peak & Slope $(\mathbf{V} / \mathbf{p H})$ & $\mathbf{n H} / \mathbf{n e}$ & $\begin{array}{c}\text { Ions } \\
\text { exchanged }\end{array}$ \\
\hline $\boldsymbol{P A N I}$ & First & -0.062 & 1 & $2 \mathrm{H}^{+} / 2 \mathrm{e}^{-}$ \\
P2ABA & First & -0.037 & 0.5 & $1 \mathrm{H}^{+} / 2 \mathrm{e}$ \\
$\boldsymbol{P A N I}$ & Second & -0.118 & 2 & $2 \mathrm{H}^{+} / 2 \mathrm{e}^{-}$ \\
P2ABA & Second & -0.101 & 2 & $4 \mathrm{H}^{+} / 2 \mathrm{e}$ \\
\hline
\end{tabular}

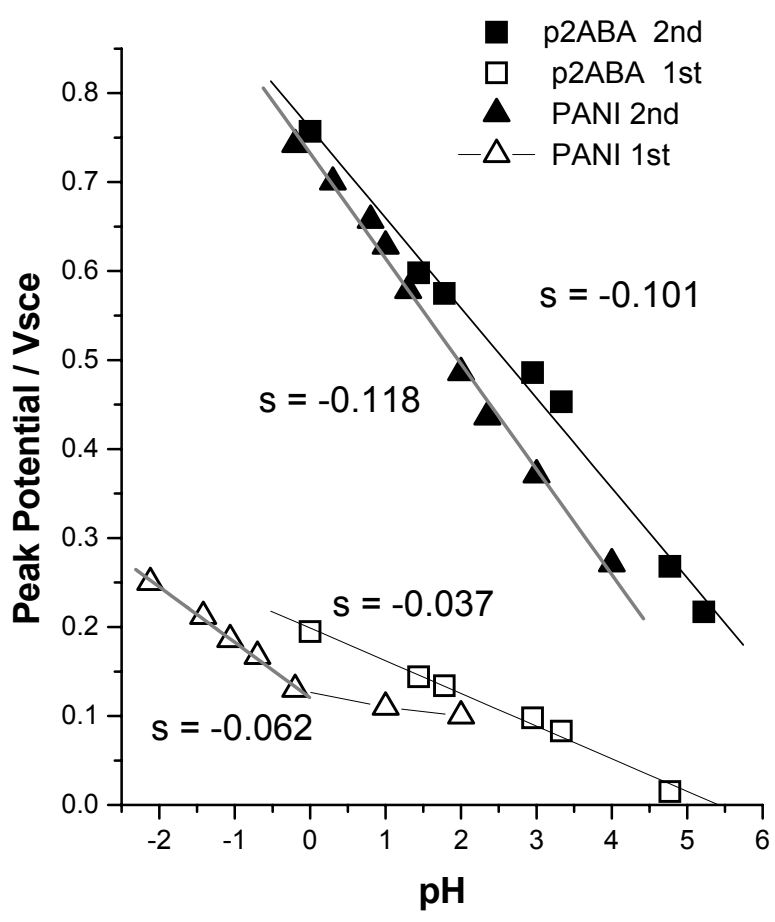

Figure 2. Dependence of the peak potential on $\mathrm{pH}$. Squares are experimental data of p2ABA11 films. Triangles are data for PANI films from Ref. 10. The values of the slopes are beside the lines. 


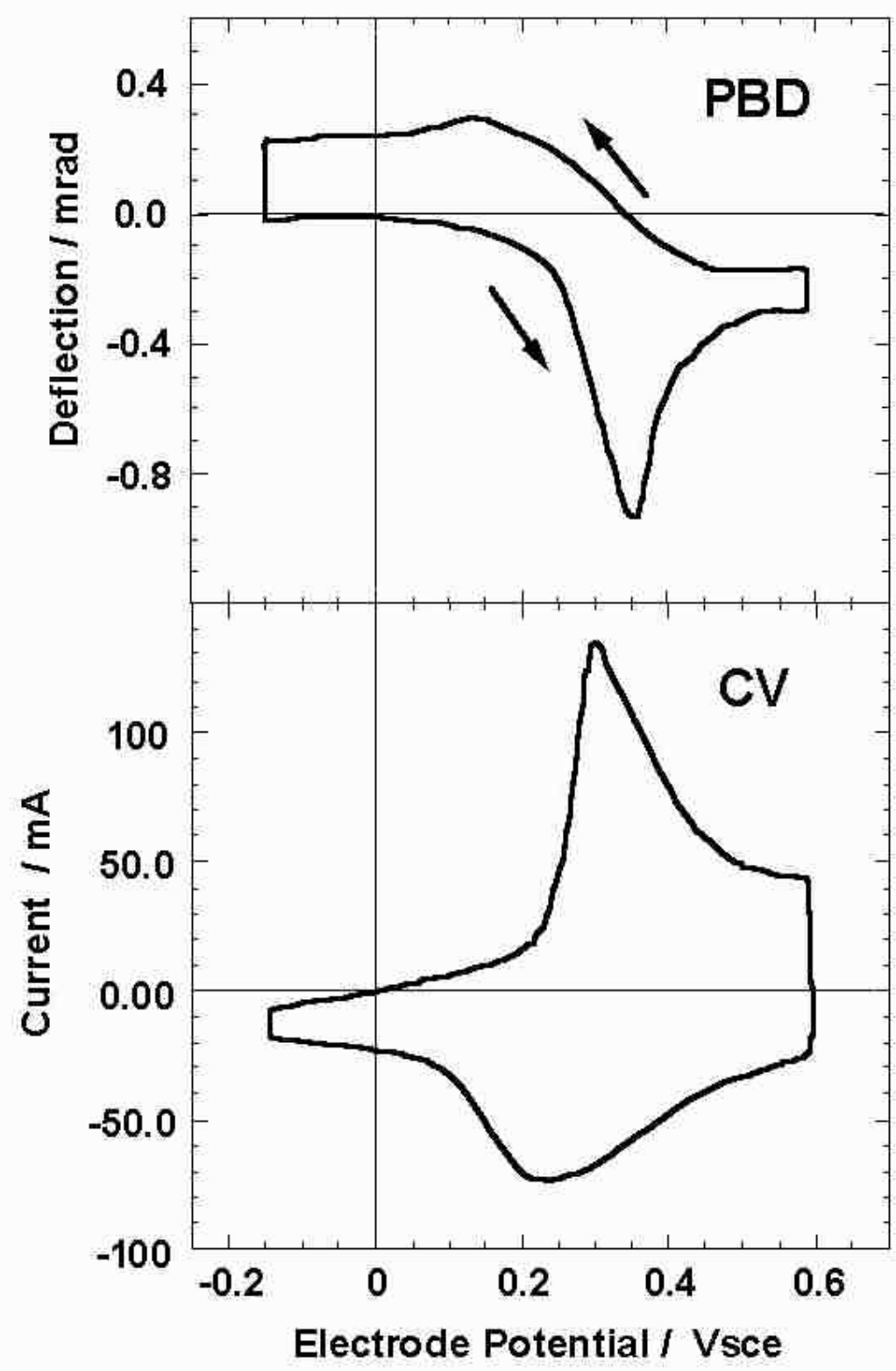

Figure 3. Cyclic voltammogram $(\mathrm{CV})$ and cyclic deflectogram (PBD) of a p2ABA modified electrode in $0.1 \mathrm{M} \mathrm{HClO} 4$. Scan rate $=50 \mathrm{mV} / \mathrm{s}$.

The proposed redox coupled ion exchange mechanism of $\mathrm{p} 2 \mathrm{ABA}$ is described in Scheme 1.

While the carboxylic group is protonated in the reduced state (leucoemeraldine), it is assumed that the carboxylic acid is deprotonated in the emeraldine state, even at $\mathrm{pH}$ 1. The $\mathrm{pKa}$ value of 2-aminobenzoic acid is 2.17 [13], suggesting that 
the carboxylic acid should be protonated at low $\mathrm{pH}$. However, due to Donnan effects, the $\mathrm{pH}$ inside the film could be higher than in solution [14]. Alternatively, the carboxylic group could form a cyclic species with the positive charge, as it has been found in sulphonated polyaniline (SPAN) [15], making it easier to deprotonate. Recent results, obtained using in-situ FTIR [16], support the existence of free carboxilate in p2ABA (emeraldine state) at low $\mathrm{pH}$.

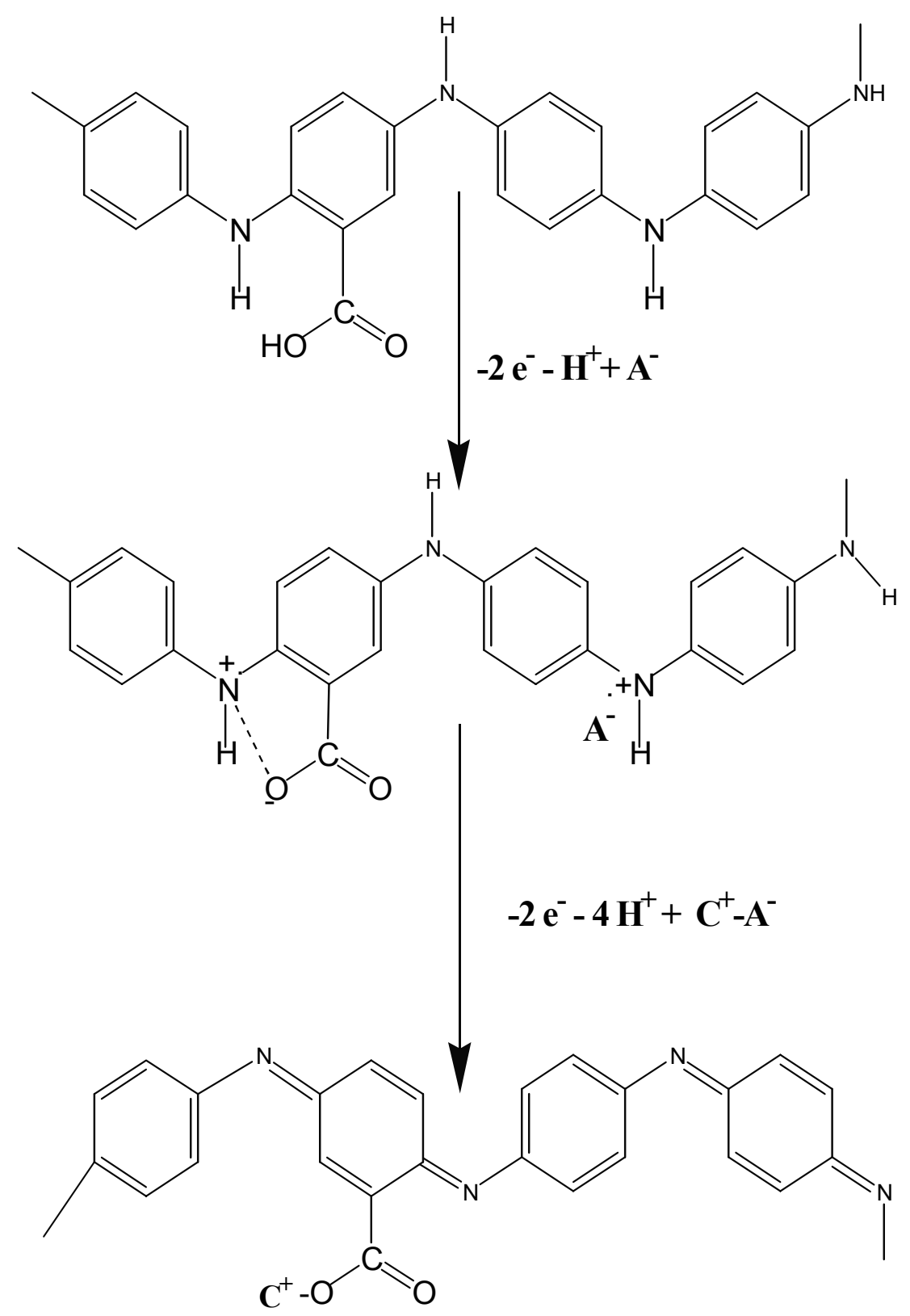

Scheme 1. Ion exchange mechanism during oxidation of p2ABA in acid media. 
The data suggest that $\mathrm{p} 2 \mathrm{ABA}$ is electroactive even at $\mathrm{pH}$, making it an interesting material for sensor building. Additionally, protons are expelled during both redox processes making the material potentially useful for $\mathrm{pH}$ actuators [17].

The present study will be extended to other compositions of $\mathrm{p} 2 \mathrm{ABA}$ and to a related copolymer: poly(aniline-co-(3-aminobenzoic acid)).

\section{Conclusions}

The redox coupled ion exchange of poly(aniline-co-(2-aminobenzoic acid)) is different to that of PANI due to the presence of the anionic group in the copolymer. It seems that, even at low $\mathrm{pH}$ solution, the carboxylic group is deprotonated and could compensate for the positive charge formed during oxidation. Therefore, proton expulsion is the dominant ion exchange during the first redox peak. The second redox process of $\mathrm{p} 2 \mathrm{ABA}$ is similar to that of PANI.

\section{Acknowledgement}

The present work was supported by FONCYT, CONICET, Agencia Córdoba Ciencia y SECYT-UNRC. H.J. Salavagione thanks FONCYT for a graduate fellowship. D.F. Acevedo thanks Agencia Córdoba Ciencia for a graduate fellowship. C. Barbero is a permanent research fellow of CONICET.

\section{References}

1. J. Yue, A.J. Epstein, J. Am. Chem. Soc. 112 (1990) 2800.

2. J. Yue, Z.H. Wang, K.R. Cromack, A.J. Epstein, A.G. MacDiarmid, J. Am. Chem. Soc. 113 (1991) 2665.

3. C. Barbero, M. C. Miras, B. Schnyder, R. Kötz, J. Mater. Chem. 4 (1994) 1775 .

4. C. Barbero, M.C. Miras, R. Kötz, J. Electroanal. Chem. 437 (1997) 191.

5. H.S.O. Chan, S.C. Ng, W.S. Sim, Thermochim. Acta 197 (1992) 349; H.S.O. Chan, S.C. Ng, W.S. Sim,K.L. Tan, B.T.G. Tan, Macromolecules 25 (1992) 6029; J-J. Xu, D-M. Zhou, H-Y. Chen, Fresenius J. Anal. Chem. 362 (1998) 234. 
6. A.A. Karyakin, I.A. Mlatsev, L.V. Lukachova, J. Electroanal. Chem. 402 (1996) 217; N. Toshima, H. Yan, Y. Gotoh, M. Ishiwatari, Chem. Lett. (1994) 2229.

7. C. Thiemann, C.M.A. Brett, Synthetic Metals 123 (2001) 1.

8. C. Barbero, M.C. Miras, O. Haas, R. Kötz, J. Electrochem. Soc.138 (1991) 669; C. Barbero, M.C. Miras, R. Kötz, Electrochim. Acta 37 (1992) 429; M.J. Henderson, A.R. Hillman, E. Vieil, J. Electroanal. Chem. 454 (1998) 1; C. Barbero, M. C. Miras, E. J. Calvo, R. Koetz, O. Haas, Langmuir 18 (2002) 2756.

9. R. Kötz, C. Barbero, O. Haas, J. Electroanal. Chem. 296 (1990) 37.

10. C. Barbero, M.C. Miras, J. Arg. Chem. Soc., in press.

11. W. S. Huang, B. D. Humphrey, A. G. MacDiarmid. J. Chem. Soc., Faraday Trans. 82 (1986) 2385.

12. C. Barbero, M.C. Miras, O. Haas, R. Kötz, J. Electrochem. Soc. 138 (1991) 669.

13. A. Albert, E.P. Serjeant, "The Determination of Ionization Constants", Chapman \& Hall, New York, 1978.

14. G.E. Asturias, G-W. Jang, A.G. MacDiarmid, K. Doblhofer, Ch. Zhong, Ber. Bunsenges. Phys. Chem. 95 (1991) 1381.

15. Q. Wu, Z. Qi, F. Wang, Synthetic Metals 105 (1999) 191.

16. H.J. Salavagione, J. Arias, E. Morallon, J.L. Vazquez, C. Barbero, to be published.

17. J. Yue, A.J. Epstein, Chem. Commun. (1992) 1540. 